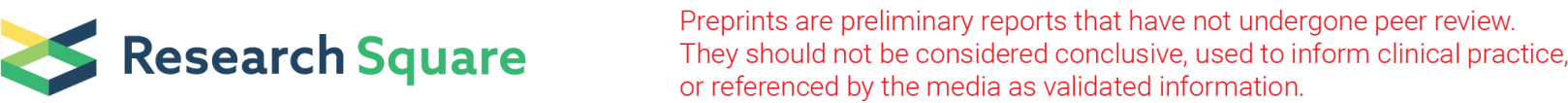

\section{Empathy and Burnout in Medical Staff: Mediating Role of Job Satisfaction and Job Commitment}

\section{Zongpu YUE}

Tianjin University of Traditional Chinese Medicine https://orcid.org/0000-0002-3541-5818

\section{Yang Qin}

Tianjin University of Traditional Chinese Medicine

\section{Ying Li}

Tianjin University of Traditional Chinese Medicine

\section{Jian Wang}

Wuhan University

\section{Stephen Nicholas}

University of Newcastle

\section{Elizabeth Maitland}

University of Liverpool School of Management: University of Liverpool Management School

Cai Liu ( $\sim$ keidy0707@163.com )

Tianjin University of Traditional Chinese Medicine https://orcid.org/0000-0002-4664-3402

\section{Research}

Keywords: Medical staff, Job burnout, Empathy, SEM, Job satisfaction, Job Commitment

Posted Date: May 4th, 2021

DOI: https://doi.org/10.21203/rs.3.rs-418989/v1

License: (c) (1) This work is licensed under a Creative Commons Attribution 4.0 International License.

Read Full License 


\section{Abstract}

Background: Burnout is a growing problem among medical staff worldwide and empathy has been described as an essential competence to attenuate burnout. Previous studies found job satisfaction and job commitment were affected by the empathy and associated with burnout. This study explores the effect and mechanism of empathy on burnout on medical staff and investigates the mediating role of job satisfaction and job commitment in the relationship between empathy and burnout among medical staff.

Methods: Based on a self-administered questionnaire, 335 responses from medical staff in Tianjin City, China, yielded data on socio-demographic characteristics, empathy, burnout, job satisfaction and job commitment. Bivariate correlation and structured equation modeling (SEM) analyzed the relationships between empathy, job satisfaction, job commitment and burnout multi-group invariant analysis was used to evaluate whether the model was consistent across different type and level of hospitals and different job and employment type subgroups.

Results: A total of $202(60.3 \%)$ medical staff had low level burnout, $115(34.3 \%)$ staff had the moderate level and 18 (5.4\%) staff had the high level burnout. The results of the SEM showed that empathy not only have a direct negative effect on burnout $(\beta=-0.401$, Pcript $>$, but also had an indirect impact through job satisfaction $(\beta=-0.373$, Pcript $>$ and job commitment $(\beta=0.489$, Pcript $>$. Job commitment was negatively associated burnout $(\beta=-0.513$, Pcript $>$ but, unexpectantly, job satisfaction was positively associated with burnout $(\beta=0.177$, Pcript $>$. The results also indicated the model was consistent across employment type $\left(\Delta \chi^{2}=5.904, p>0.05\right)$ and hospital type $\left(\Delta \chi^{2}=\right.$ $7.748, p>0.05)$, but was inconsistent across hospital level $\left(\Delta \chi^{2}=42.930, p<0.05\right)$ and job type $\left(\Delta \chi^{2}=\right.$ $52.912, p<0.05)$.

Conclusions: Our results confirm the important role that empathy plays in the prevention of burnout and by managing job satisfaction and increasing the job commitment burnout can be attenuated. We recommend that government should increase pay for medical staff and continue to reform the resourcing of different hospital levels and that hospital managers implement additional training and strengthening psychological testing and counseling, to reduce medical staff burnout.

\section{Background}

Burnout, or when individuals experience chronic work-based stress for which the perceived job demands exceed personal and work-place resources, is common among medical workers [1]. Research has identified burnout across a wide range of healthcare professions, including UK consultants [2], ear nose and throat surgeons [3], doctors [4] and psychiatric nurses [5]; Spanish oncology health professionals [6]; Singapore mental health workers [7]; and Australian clinical psychologists [8]. American doctors experience some of the fastest increasing burnout rates in the world, with one study estimating burnout at $40 \%$ in $2013,46 \%$ in early 2015 and $65 \%$ in 2016 [9], and estimated burnout rates among U.S. palliative care staff varied widely from 9-61\% [10]. Burnout among medical staff in Heilongjiang varied between 
$53 \%$ and $85 \%$ [11] and the Beijing young medical staff burnout rate was estimated at $65.1 \%$ [12]. One Chinese study found burnout reached $91.3 \%$ in the department of infectious disease in Wuhu [13] and $76.9 \%$ of Chinese physicians reported symptoms of burnout [14]. Burnout has been linked to a decline in work performance, poorer health, staff sickness, mental illness, job separation and high turnover rates, decreased patient satisfaction and increased medical errors $[15,16]$.

The health care literature has explored the factors attenuating medical staff burnout, including empathy, work commitment and work satisfaction. Empathy is a unique phycological resource because of its impact both on patients and medical staff. Through the formation of personal relationships and enhanced communication with patients [17], empathy improves the doctor-patient relationship, resulting in better patient confidence in and compliance with treatment [18]. Since empathy helps to prevent physical and emotional workload exhaustion [19], doctors with high levels of empathy may be more resistant to burnout [20]. Many studies have investigated empathy as a predictive variable of burnout [21, $22]$ and burnout has been associated with a decline of empathy [23, 24]. For example, a study of primary care professionals in Spain found that higher levels of empathy were associated with lower burnout [25]. Studies have explored the relationship between empathy and three dimensions of burnout: empathy reduces job burnout in general [26]; empathy is negatively correlated with emotional exhaustion and depersonalization; and empathy is positively correlated with personal accomplishment [27]. We propose:

H1: Empathy has a negative association with burnout.

In the burnout literature, many factors have been associated with burnout in medical staff, including sex, working hours, the presence of work-home conflict, coping strategies, staff perceptions, job commitment and job satisfaction [28]. Job satisfaction and job commitment have a major influence on job-related behaviors, such as job resignation, absenteeism, job performance and burnout [29, 30]. For example, burnout scale items have been found to be negatively and directly linked to job satisfaction [31] Burnout dimensions, such as emotional exhaustion and low personal accomplishment have been shown to be negatively associated with job satisfaction [32]. By understanding job satisfaction and its relationship with burnout, employee behavior can be positively influenced, which contributes to improved hospital performance and employee well-being [33]. The burnout literature has also argued that job commitment can insulate those who form a strong bond with their organization from experiencing burnout, with job commitment negatively associated with burnout [34-36]. As well as attenuating burnout, job commitment can also be harnessed to improve work and hospital performance. Empathy can impact both job satisfaction and job commitment. For example, empathy makes practicing medicine more meaningful, enhancing the sense of usefulness among medical staff, ensuring better job satisfaction and attenuating burnout [24,37-38] Similarly, empathy and burnout could be mediated by job commitment [39]. One study found that with more years of experience and greater job commitment, there is a sequential increase in nurses' empathy, so variations in job commitment can improve the relationship between empathy and burnout $[39,40]$. Raiziene et al [41] found empathy was positively associated with occupational commitment, and they both were negatively associated with burnout. We propose: 
H2a: Empathy has a positive effect on job satisfaction.

H2b: Job satisfaction negatively mediates the relationship between empathy and job burnout.

H3a: Empathy has a positive effect on job commitment

H3b: Job commitment negatively mediates the relationship between empathy and job burnout

Based on the above discussion, Fig. 1 provides a diagrammatic representation linking burnout, empathy, job satisfaction and job commitment relationships, where empathy decreases burnout and job satisfaction and job commitment mediate the empathy-burnout relationship.

Our study extends the empathy-burnout literature in several ways. Previous studies have mainly focused on the relationship between job burnout and empathy, or job commitment and job satisfaction and burnout. Few studies have focused on the mediating effect of variables on the empathy-burnout relationship. Constructing a mediated structural equation model, we extend the burnout literature by assessing whether job satisfaction and job commitment mediated the relationship between empathy and

job burnout. Second, most burnout studies have collected data on one type of health professional, such as doctors or nurses, in a specific health setting, such as nursing homes or hospitals [42]. Our study collected data on all medical staff, including physicians, nurses and clinical pathologists, across different hospital levels and different hospital types in Tianjin, China. Finally, our study extends the literature by conducting a multi-group invariance analyses after the structure equation modeling to determine whether hospital type, hospital level, job positions and employment type affected the mediated model. If there were differences across hospital type and level and across job positions, managers should set different policies according to different hospital and medical groups to reduce burnout. To evaluate whether the model in Fig. 1 holds across hospitals levels and types and different positions and employment types, we propose:

H4: The model in Fig. 1 is applicable to different hospital types, hospital levels, job positions and employment types.

\section{Methods}

\section{Participants And Settings}

Using cluster sampling, we conducted a pilot survey to assess the robustness and validity of our variables and the framing of our questions, before undertaking face-to-face and online surveys of medical professionals in Tianjin, China from July 1, 2019 to September 8, 2019. Respondents could scan the QR code on their mobile phones to complete the survey or fill out paper questionnaires. In order to improve the accuracy of the survey responses, the survey purpose, method and the conceptual basis of each variable was explained to participants. The inclusion criteria of participants captured physicians, nurses, medical technicians, pharmacists, administrators and other medical personnel with more than 1 year of work experience engaged in medical and health work in Tianjin public medical and health 
institutions. All participants were volunteers, who gave informed consent to participate and were capable of completing the questionnaire independently. The responses by participants were anonymous.

The minimum sample size was calculated as 270 completed surveys [43-45]. Of the 350 distributed surveys, 15 uncompleted and inaccurate questionnaires were excluded, providing 335 valid responses, with a $95.71 \%$ effective response rate. Of the 335 valid questionnaires, 121 were completed online and 214 were completed using paper questionnaires. There were no significant differences in the responses between the online and paper questionnaires.

\section{Measures}

The questionnaire had five parts: job burnout, empathy, job satisfaction, job commitment and the respondent's social-demographic characteristics, comprising age, sex, educational background, marital status, salary, workplace, professional titles and average daily working hours. The content of each scale is presented in Supplementary Table 1. Tianjin hospitals were categorized into three types: primary hospitals, equipped with less than 100 beds, only providing basic health services for a mainly local community; secondary hospitals, usually equipped with more than 100 , but less than 500 , beds, providing comprehensive medical services to several communities, with some teaching and scientific research activities; and tertiary hospitals, usually with more than 500 beds, considered a regional hospital providing high-level, specialty medical services to several districts, as well as performing higher level medical education and significant scientific research. Hospitals were also divided into two types, either specialist or general hospitals. Data on employment type (authorized and unauthorized) and job position were also collected.

\section{Job burnout}

To measure burnout, we employed the most commonly used burnout scale, the Maslach Burnout Inventory (MBI) [46]. Comprising a total of 22 items, MBI contained three key dimensions, 'Emotional Exhaustion', 'Dehumanization' and 'Low-Personal Accomplishment', measured on a 7-point Likert scale (1never to 7-every day). The emotional exhaustion and dehumanization items were scored positively, with higher scores indicating a higher degree of job burnout, and the low personal achievement items used the reverse scoring method, with the lower the score, the higher the degree of job burnout. After the Confirmatory Factor Analysis, we deleted the items which coefficients are less than 0.6 , yielding four 'Emotional Exhaustion' variables and four 'Dehumanization' variables and six 'Low-Personal Accomplishment' variables. We defined low burnout as a value less than 3 on the MBI scale; medium level burnout between 3 and 5 on the MBI scale; and high level burnout as greater than 5 on the $\mathrm{MBI}$ scale.

\section{Empathy}

Empathy of medical staff was measured by the Chinese version of the Jefferson Scale Empathy - Health Professions (JSE-HP) [47]. The 20 item scale was divided into three dimensions: perspective-taking(PT), 
compassionate care (CC) and standing in patients' shoes (SIPS). The items in perspective-taking were understanding the emotions of patients and their families, empathy, attention to body language; items in compassionate care were the ability to understand and empathize with patients and help patients in timely manner, such as treating patients on the basis of understanding their emotions, paying attention to emotional changes when asking about their condition and considering patient's personal experience; and standing in patients' shoes referred to the ability of medical staff to think from the patient's perspective, including treating the problem from the patient's perspective and thinking from the patient's perspective. The scale included response categories from 1-completely disagree to 7-completely agree, with the emotional care scale and considerate ability scale reverse scored.

\section{Job satisfaction}

Adopted from Zhang et al [48, 49], the job description index (JDI) scale measured the medical staff's job satisfaction, based on five dimensions: the satisfaction with the job itself, promotion, salary, manager and partner. In the interviews with participants in the pilot survey, one common feedback was that the doctor-patient relationship could influence them significantly, so we added "job environment" into the original scale. Therefore, the augmented JDI scale included a 6-dimensions scale, measured by a 5-point Likert scale (1-very dissatisfied to 5-very satisfied), with a higher score indicating the more job satisfied the respondent.

\section{Job commitment}

To measure job commitment, we used Meyer's three-dimensional scale, comprising 'Emotional Commitment', 'Continuous Commitment' and 'Normative Commitment' items, and measured by a 5-point Likert scale (1-very dissatisfied to 5-very satisfied).

\section{Multi-group analysis}

To test multi-group invariance, we divided our sample into three different hospital levels (primary hospital, secondary hospital and tertiary hospital); two hospital types (general hospital and specialty hospital); three job positions (physician, nurse and other medical staff); and two employment types (authorized employees who entered the hospital or institutions by passing the formal examination and had registered in the China Organization Department and Ministry of Human Resources and unauthorized employees).

\section{Statistical analysis}

Data entry and conversion was completed with EpiData 3.1 and SPSS 24.0 (IBM Corp, Armonk, NY, USA) and AMOS 23.0 (IBM Corp, Armonk, NY, USA) was used to analyze the data. Descriptive analyses explored the key social demographic factors and the degree of job burnout of medical staff. Next, a structural equation model (SEM) was specified to analyze empathy and job burnout, mediated by job satisfaction and job commitment. Based on the SEM, a multi-group equivalence analysis was conducted to determine the impact of different types and levels of hospital, job positions and employment types on the model. In the process of model fitting, 5000 Bootstrap tests to the mediating variables were 
conducted; observed variables with path coefficients less than 0.6 were deleted; and the modification index (MI) was used to optimize the model. Cronbach's alpha values of each dimension and the overall scale were greater than 0.7 , indicating good factor reliability. Most of the average variance extracted (AVE) values were greater than 0.5 , indicating good aggregation validity of the model [126].

\section{Results}

\section{Descriptive Statistics}

The socio-demographics of the 335 medical staff who completed the survey are presented in Table 1. Ranging from 18 to 66 years old, the average age was $37.65 \pm 10.65$ years; $45 \%$ were physicians (which requires a bachelor degree or above); the majority (54\%) had achieved a bachelor degree and $5.1 \% \mathrm{had}$ a PhD degree; $94 \%$ worked more than 6 hours per day; and just over half (54.3\%) earned more than RMB6000 per month, with $3.9 \%$ paid more than RMB15000 per month. 
Table 1

Demographics characteristics of the sample $(\mathrm{N}=335)$

\begin{tabular}{|c|c|c|c|}
\hline Variables & Group & Frequency & Percent \\
\hline \multirow[t]{2}{*}{ Gender } & Male & 178 & $53.1 \%$ \\
\hline & Female & 157 & $46.9 \%$ \\
\hline \multirow[t]{4}{*}{ Education background } & Doctor and above & 17 & $5.1 \%$ \\
\hline & Master & 65 & $19.4 \%$ \\
\hline & Bachelor & 181 & $54.0 \%$ \\
\hline & College degree & 73 & $21.5 \%$ \\
\hline \multirow[t]{4}{*}{ Marital status } & Unmarried & 81 & $24.3 \%$ \\
\hline & Married & 243 & $72.5 \%$ \\
\hline & Divorced & 7 & $2.1 \%$ \\
\hline & Widowed & 4 & $1.2 \%$ \\
\hline \multirow[t]{3}{*}{ Number of children } & 0 & 104 & $31.0 \%$ \\
\hline & 1 & 196 & $58.5 \%$ \\
\hline & 2 and above & 35 & $10.4 \%$ \\
\hline \multirow[t]{3}{*}{ Hospital level } & Tertiary & 201 & $60.0 \%$ \\
\hline & Secondary & 76 & $22.7 \%$ \\
\hline & Primary & 58 & $17.3 \%$ \\
\hline Hospital type & General & 233 & $69.6 \%$ \\
\hline \multirow[t]{7}{*}{ Job position } & Specialist & 102 & $30.4 \%$ \\
\hline & Physician & 152 & $45.4 \%$ \\
\hline & Nurse & 75 & $22.7 \%$ \\
\hline & Medical technician & 25 & $7.5 \%$ \\
\hline & Pharmacist & 25 & $7.5 \%$ \\
\hline & Administrator & 34 & $10.1 \%$ \\
\hline & Others & 23 & $6.9 \%$ \\
\hline \multirow[t]{2}{*}{ Employment type } & Authorized & 252 & $75.2 \%$ \\
\hline & Unauthorized & 83 & $24.8 \%$ \\
\hline Monthly income (RMB) & $<2000$ & 18 & $5.4 \%$ \\
\hline
\end{tabular}




\begin{tabular}{|llll|}
\hline Variables & Group & Frequency & Percent \\
\hline $2000 \sim 4000$ & 45 & $13.4 \%$ \\
\hline $4001 \sim 6000$ & 90 & $26.9 \%$ \\
\hline $6001 \sim 10000$ & 117 & $34.9 \%$ \\
\hline $10001 \sim 15000$ & 52 & $15.5 \%$ \\
\hline$>15000$ & 13 & $3.9 \%$ \\
\hline Working hours per day & $<6$ & 20 & $6.0 \%$ \\
\hline $6-9$ & 240 & $71.6 \%$ \\
\hline $9-12$ & 58 & $17.3 \%$ \\
\hline$>12$ & 17 & $5.1 \%$ \\
\hline
\end{tabular}

There were 202 (60.3\%) staff with low level burnout, 115 (34.3\%) staff with the moderate level and 18 (5.4\%) with the high level burnout. Table 2 shows the breakdown in burnout percentages by job position. The low level burnout varied between $36.0 \%$ for medical technicians to $76 \%$ for pharmacists. Medical technicians experienced the highest rate of moderate level burnout $(60.0 \%)$, followed by other medical staff (43.5\%), with pharmacists (20.0\%) displaying the lowest moderate burnout level. High level burnout ranged from $8.7 \%$ for other medical staff, $5.9 \%$ for administrators to $4.0 \%$ for both medical technicians and pharmacists.

Table 2

Burnout level by the job position

\begin{tabular}{|lllllll|}
\hline & Physician & Nurse & $\begin{array}{l}\text { Medical } \\
\text { technician }\end{array}$ & Pharmacist & Administrator & Others \\
\hline Low Level (\%) & 66.4 & 56.6 & 36.0 & 76.0 & 55.9 & 47.8 \\
$\begin{array}{l}\text { Moderate Level } \\
\text { (\%) }\end{array}$ & 28.3 & 38.2 & 60.0 & 20.0 & 38.2 & 43.5 \\
\hline High Level (\%) & 5.3 & 5.3 & 4.0 & 4.0 & 5.9 & 8.7 \\
\hline
\end{tabular}

Table 3 shows the total score of job burnout of medical staff was 2.853 out of 7 , which was lower than the median intensity (4 points) indicating that the overall extent of job burnout was low. All the burnout dimension sub-scores (emotional exhaustion 2.783, dehumanization 2.802, and low personal achievement 2.973) were also low. Pearson correlation analysis showed that all three dimensions of job burnout were positively correlated with overall job burnout $(p<0.01)$, and the highest correlation was emotional exhaustion $(r=0.933)$. 
Table 3

Dimensions scores and total scores in job burnout

\begin{tabular}{|llllll|}
\hline Dimensions & $\begin{array}{l}\text { Number of } \\
\text { items }\end{array}$ & Mean & SD & $\begin{array}{l}\text { Pearson } \\
\text { correlation } \\
\text { Coefficient } \\
\text { with job burnout }\end{array}$ & $\begin{array}{c}\text { Burnout } \\
\text { percent }\end{array}$ \\
\hline Emotional exhaustion & 4 & & & & \\
\hline Dehumanization & 4 & 2.783 & 1.498 & $.933^{\star *}$ & $22.09 \%$ \\
\hline $\begin{array}{l}\text { Low personal } \\
\text { achievement }\end{array}$ & 6 & 2.802 & 1.484 & $.925^{\star *}$ & $23.58 \%$ \\
\hline Total job burnout & 14 & 2.973 & 1.269 & $.834^{\star *}$ & $10.70 \%$ \\
\hline Note: ** $\mathbf{p}<\mathbf{0 . 0 1}$ & & 2.853 & 1.276 & 1.000 & \\
\hline
\end{tabular}

\section{Correlation Analysis}

Table 4 displays the correlation analysis results for medical staff empathy, job commitment, job satisfaction and job burnout. Empathy was significantly, and negatively, correlated with job burnout and job satisfaction and positively correlated with job commitment $(p<0.01)$. Job burnout was also significantly negatively correlated to job commitment and job satisfaction $(p<0.0, r<0)$ and job commitment and job satisfaction were negatively correlated. $(p<0, r<0)$.

Table 4

Correlation analysis among empathy ability, job burnout, job commitment and job satisfaction

\begin{tabular}{|lllll|}
\hline Variables & Empathy & Job burnout & Job commitment & Job satisfaction \\
\hline Empathy & 1.000 & & & \\
\hline Job burnout & $-.701^{\star \star}$ & 1.000 & & \\
\hline Job commitment & $.637^{\star \star}$ & $-.769 \star \star$ & 1.000 & 1.000 \\
\hline Job satisfaction & $-.330^{\star \star}$ & $.610^{\star \star}$ & $-.512^{\star \star}$ & \\
\hline Note: ${ }^{\star *} \mathrm{p}<0.01$ & & & & \\
\hline
\end{tabular}

\section{Structural Equation Modeling}

According to Fig. 1, empathy not only directly affects medical staff's job burnout (H1), job satisfaction $(\mathrm{H} 2 \mathrm{a})$ and job commitment (H3a), but also has an indirect effect on job burnout through job satisfaction $(\mathrm{H} 2 \mathrm{~b})$ and job commitment $(\mathrm{H} 3 \mathrm{~b})$, where job satisfaction and job commitment play a mediating role in 
the relationship between empathy and job burnout. The six paths are shown in the full structural equation model Fig. 2: (1) Path a represents the total effect of empathy (E) to job burnout as specified in Hypothesis 1 ; (2) Path b represents the indirect effect of empathy to job satisfaction (H2a); Path c represents the indirect effect of empathy to job commitment ( $\mathrm{H} 3 \mathrm{a})$; (3) Path $d(\mathrm{H} 2 \mathrm{~b})$ and Path e $(\mathrm{H} 3 \mathrm{~b})$ are the paths from potential mediating variable to dependent variable; (4) Path $f$ specifies the relationship between the two mediating variables, representing the effect of job satisfaction on job commitment; and (5) A1-3, B1-3 and C1-3 are the dimensions of empathy, job commitment and job burnout, and (6) e1-9 represent the error terms of every dimension.

We revised the model when some of the fitting indices did not meet the fitting criteria, indicating that the path map Fig. 2 was not ideal. According to the amendment advice given by AMOS, we added bidirectional arrows to improve model fit. The final fitting indices were $\chi^{2} / d f=2.80, A G F I=0.914, G F I=$ $0.937, C F I=0.986, T L I=0.964, R M S E A=0.073$, all of which meet the AMOS reference criteria [50]. The coefficients of the 6 paths are shown in Table 5 and the revised standard path map is displayed in Fig. 3, which shows the relationship and loading coefficient among empathy, job satisfaction, job commitment and job burnout.

As shown in Fig. 3, the standardized path coefficient of empathy to job burnout is -0.401 indicates that empathy is negatively correlated with job burnout, which confirms $\mathrm{H} 1$. The standardized path coefficient of empathy to job commitment is 0.489 , revealing that job commitment was positively correlated with empathy, confirming $\mathrm{H} 2 \mathrm{a}$. But empathy had a negative effect on job satisfaction, where the coefficient was -0.373 , which is the opposite of $\mathrm{H} 3 \mathrm{a}$. Job burnout decreased by 0.513 units for each additional unit of job commitment and increased by 0.177 units for each additional unit of job satisfaction.

Table 5

The test of path coefficient ${ }^{a}$ by MLE

\begin{tabular}{|llllll|}
\hline Path & \multicolumn{3}{c}{ Non-standardized coefficient } & \multicolumn{2}{l|}{ Standardized coefficient } \\
\cline { 2 - 6 } & Unstd. & S.E. & C.R. & $P$ & Std. \\
\hline Job satisfaction $\leftarrow$ Empathy & -.355 & .053 & -6.717 & $\mathbf{0 . 0 0 1}$ & -.373 \\
\hline Job commitment $\leftarrow$ Empathy & .532 & .056 & 9.428 & $\mathbf{0 . 0 0 1}$ & .489 \\
\hline Job commitment $\leftarrow$ Job satisfaction & -.487 & .049 & -9.976 & $\mathbf{0 . 0 0 1}$ & -.426 \\
\hline Job burnout $\leftarrow$ Empathy ability & -.619 & .088 & -7.043 & $\mathbf{0 . 0 0 1}$ & -.401 \\
\hline Job burnout $\leftarrow$ Job commitment & -.727 & .098 & -7.408 & $\mathbf{0 . 0 0 1}$ & -.513 \\
\hline Job burnout $\leftarrow$ Job satisfaction & .287 & .067 & 4.288 & $\mathbf{0 . 0 0 1}$ & .177 \\
\hline Note: a standardized path coefficient & & & & & \\
\hline
\end{tabular}


Each path of the mediating variables was guided by 5000 repetitions of the Bias-corrected Bootstrap test and Percentile Bootstrap test. Supplementary Table 2 shows the significance test results of the pathways between empathy, job burnout, job satisfaction and job commitment. Regarding the pathway between empathy and job burnout, the mediation effect of job satisfaction on the relationship of empathy and job burnout was positive $(p<0.01), 95 \% \mathrm{Cl}$ : $(-0.544)-(0.269)$, which was opposite to $\mathrm{H} 2 \mathrm{~b}$. Job commitment had a negative mediation effect, $95 \% \mathrm{Cl}$ : $(-0.159)-(-0.041)$, which supports $\mathrm{H} 3 \mathrm{~b}$.

\section{Multi-group Invariance Analysis}

The multi-group invariance analysis tests whether the model is consistent across different subgroups, comprising different types of hospital, different levels of hospital, different medical jobs and different employment types. When there are (in)significant differences between different subgroup sample coefficients, the research model parameters are (in)variant, indicating that the multi-group model is (in)consistent across different subsamples.

Based on primary, secondary and tertiary hospital level, the results show that hospital level had a significant impact on the empathy and job burnout $\left(\Delta \chi^{2}=42.930, \mathrm{p}<0.05\right)$. With regard to job satisfaction-job commitment path, the tertiary hospitals and secondary hospitals differed significantly compared to primary hospitals $(p<0.001)$. As shown in Supplementary Table 3 , the influence of tertiary and secondary hospitals was greater than that of primary hospitals, and secondary hospitals were more influential than tertiary hospitals. On job satisfaction-job burnout path, secondary hospitals and primary hospitals displayed significant differences $(p<0.05)$, with the influence of the secondary hospital significantly greater than that of primary hospitals.

Next, we tested whether medical job type impacted empathy, job commitment and job satisfaction by dividing the sample into three medical occupation types: physician, nurse and other medical staff. The multi-group nested model indicated that different job type had a significant impact on empathy and job burnout model $\left(\Delta \chi^{2}=52.912, p<0.05\right)$. Supplementary Table 4 shows that there was a significant difference on the path of empathy-job burnout path among physicians and nurses $(p<0.01)$ and between nurses and other medical staff $(p<0.05)$. The nurse group had a significant impact on the prediction of job burnout $(p<0.001)$, while the physician group impact was not significant. The model showed that the influence of nurses was greater than that of physicians and other medical staff. On the job commitment-job burnout path, there was a significant difference between physicians and nurses ( $p$ $<0.001)$, between nurses and other medical staff $(p<0.05)$, and between physicians and other medical staff $(p<0.001)$. The influence of nurses was greater than that of physicians and other medical staff on the empathy-job commitment $(p<0.05)$. Further, the job satisfaction of physicians $(p<0.05)$ and other medical staff $(p<0.001)$ had a greater impact on job commitment than nurses' job satisfaction, and other medical staff had more influence than physicians on job commitment $(p<0.001)$.

We also explored whether the employment type of medical staff impacted the model. Medical staff were divided into authorized and unauthorized employment types. First, the structural equation model $\left(\chi^{2} / d f=\right.$ $1.708, N F I=0.966, G F I=0.958, C F I=0.985, T L I=0.972, R M S E A=0.046)$ revealed consistency across 
different employment types, which showed the empathy and job burnout model were not affected by employment type. Finally, hospitals were divided into two types, specialty hospitals and general hospitals. The structure weight model test showed a good fit $\left(\chi^{2} / d f=2.178, N F I=0.957, G F I=0.947, C F I=0.976\right.$, $T L I=0.953, R M S E A=0.059$.), which means that the empathy and job burnout model was not affected by hospital type. These results show that the model was consistent across employment types and hospital type, which partly confirms $\mathrm{H} 4$. The model was not consistent across hospital level and job type.

\section{Discussion}

The low level burnout rate was $60.3 \%$, the moderate level burnout rate was $34.3 \%$ and the high level burnout rate was $5.4 \%$. Our burnout rates were lower than French mental healthcare low level burnout (77.5\%); higher than the French moderate level burnout (17.8\%); and roughly the same as the French high level burnout (4.6\%) [51] and consistent with the rates for Spanish physicians and nurses, where the low level burnout rate was $58.8 \%$, the moderate level was $37.5 \%$ and the high level was $3.7 \%$ [21]. For medical staff in Heilongjiang, the moderate and high level burnout rate was $84.62 \%$ and significantly higher than Pakistani postgraduate trainees and house officers' high level burnout rate of $29.8 \%[52,53]$

\section{Influencing Factors Of Burnout}

We found significant differences in burnout according to age, marital status and working hours. Medical staff aged 56-66 years had the highest levels of job burnout. This finding is consistent with the argument that burnout is a gradual process, with the decline of job freshness and the increase of job challenges and difficulties, making medical staff more prone to burnout [54]. But the job burnout of 2635 year old medical staff was higher than those 36-45 years old. This might reflect a bimodal function, where younger age medical staff are especially prone to burnout at the beginning period of their career, which makes participation in further education and training in managing workplace stress as important as training to improve work skills [55]. Job burnout of married medical staff was lower than that of the unmarried, probably related to family support attenuating job burnout [56]. Predictably, job burnout was highest for those working more than 12 hours, with long working hours, heavy workloads and repetitive work correlated with burnout [57]. Burnout was greater for those working below 6 hours per day than those who working 6-9 hours, which might reflect those working less than 6 hours per day not interacting with patients and their daily work may be more monotonous, such as dispensing drugs, or lacking technical content, such as administrative work [58]. Further, the salary of staff who working below 6 hours, such as pharmacist and administrative workers, was always less than doctors and nurses, with dissatisfaction with lower salary related to more burnout [59].

\section{Empathy And Burnout}

The bivariate spearman correlation analysis of job burnout, empathy, job satisfaction and job commitment showed empathy was negatively correlated with job burnout (pष0.01), which is consistent with $\mathrm{H} 1$ and previous research $[71,73]$. Medical staff with higher empathy have a closer relationship with their patients, approach their job with more energy and enthusiasm, and are more likely to put themselves 
in the position of patients, possibly explaining why they were prone to low emotional exhaustion and depersonalization [60]. Medical staff who respond better to patient demands and solved patient problems will feel greater personal accomplishment, which can attenuate burnout.

\section{Job Satisfaction And Job Commitment}

The structural equation modelling tested for direct and indirect path effects. Empathy was positively correlated with job commitment $(p<0.01)$, which is consistent with the previous research [61] and confirms $\mathrm{H} 2 \mathrm{a}$. When medical staff have high empathy, they can better understand the patient and seek more measures to cure their patients, deepening their professional knowledge and enhancing their job commitment. We also found that job burnout was significantly negatively correlated with job commitment $(p<0.01)$, where increasing the job commitment of medical staff can shield health workers from burnout [62]. Through job commitment, medical staff can moderate their emotions [61], which reduces burnout, even when facing a long-term heavy workload. Job commitment provides a deeper understanding of their own behavior when dealing with colleagues and communicating with patients and patients' families, which attenuates burnout [62].

The mediating role of job satisfaction in the relationship of empathy and job burnout was inconsistent with previous research [63-65]. We found that job satisfaction negatively related with job burnout, contradicting $\mathrm{H} 3 \mathrm{a}$, which can perhaps be explained by our job satisfaction scale used and our sample characteristics [66]. Empathy is one requirement of medical staff in the process of completing their daily work [67], but by using empathy to confront illness and death every day, the medical staff may be emotionally touched and overwhelmed by helplessness and powerlessness, causing dissatisfied with their work and working environment. The more doctors try to understand their patients, and the more responsible they feel, the more likely they are to criticize themselves and to become dissatisfied with their work.

\section{Hospital Level And Job Position}

Regarding the results of multi-group invariance analysis, hospital level and job position played a moderating role in our model. We found that the job satisfaction-job commitment and job satisfactionjob burnout paths for tertiary hospitals and secondary hospitals were significantly different $(p<0.001)$, while primary hospitals were not $(p<0.001)$. The heavy workload in primary hospitals, with a shortage of staff, lower salaries and the lack of social security and training opportunities, led to a decline in management efficiency and low service capabilities [68], so medical staff in primary hospital were not satisfied with their work. This result conforms to a nationwide survey of primary care doctors in China's rural regions, which found that $70 \%$ of village doctors were unsatisfied with their income, had no hope of promotion and lacked social security after retirement [69].

The predicted effect of empathy on job burnout and job commitment on nurses was greater than that on physicians and other medical staff, which is consistent with previous research [70]. Empathy is more important in nurses' work than that of other medical staff, and nurses are better at thinking from the 
perspective of patients because of their training and their constant contact with patients [71], which contributes to job burnout. Also, the income gap between nurses and physicians was likely to lead to burnout [72]. We also found that the effect of job commitment-job burnout of physicians and other medical staff was stronger than nurses. Non-China studies have shown that there was no significant difference in job burnout among physicians, nurses and other medical staff [73], but Chinese research found that different types of medical staff revealed different attitudes towards patients. Compared to nurses who were more closely connected with patients, physicians tend to act in a non-personal way around patients, which promoted doctor depersonalization and job burnout [74]. Experiencing a high workload, physicians faced numerous patients daily, acting as both as the main diagnosticians of illness and decision-maker for treatment, creating high job commitment pressure, which can lead to job burnout.

\section{Employment Type And Hospital Type}

Our results found that employment type and hospital types did not influence the empathy-job burnout relationship, which indicates cross-group consistency. There are few previous SEM studies on the relationship between employment type and hospital types and empathy-job burnout. One study of Chinese medical staff found that authorized staff were more likely to suffer burnout from more work and higher requirements than the unauthorized staff [75]. However, we found that there was no significant difference between employment types. Due to the high employment pressure, even unauthorized employees made the same efforts as authorized staff to gain promotion, and their enthusiasm was not less than authorized staff. The fact that all medical staff both in general and specialty hospitals, faced a similar heavy workload, may explain the absence of significant differences between different types of hospitals, which confirmed $\mathrm{H} 4$ for these employees.

\section{Suggestions}

Our results suggest that the government should improve the basic salary of medical staff, especially nurses, and increase payments for extra work time and for work efficiency. Second, there was a shortage of medical staff, especially staff working in primary hospitals. The government should increase the training of medical staff, paying special attention to the training of staff in primary health care facilities. Third, further reforms should establish an integrated health care system to relieve the workload on medical staff. This would require the reallocation of resources between different hospital levels, correcting the concentration of resources in tertiary urban hospitals at the expense of rural primary health care facilities. Workload issues also arise from the over-use of tertiary and secondary hospitals when patients choose higher level hospitals even for minor medical problems, rather than using primary health care facilities as gatekeepers. Finally, hospitals should identify and support medical staff subject to burnout by strengthening psychological testing and counseling. Since our results showed burnout varied by age, these support facilities should be age specific.

Hospital managers should enhance the job commitment of their medical staff by creating a good working environment, carrying out progressive education and giving medical staff training and learning opportunities and expanding opportunities for their career development. Through the establishment of a 
scientific shift-work systems, hospital managers should set the maximum daily working hours to avoid excess work hours and reduce the workload. At the same time, hospital managers can promote activities between different departments to create the formation of good cooperative relations among medical staff to improve their empathy ability.

\section{Limitations}

Three limitations of the study should be addressed. First, although the SEM was used to quantitatively verify the relationship between variables, the use of cross-section data limited drawing causality conclusions. Second, we only surveyed medical staff in Tianjin, and generalizing our results for other cities and regions, especially rural areas, requires further study. Third, our findings are largely based on the self-assessment questionnaires, with the risk that the participants' answers might have been affected by response and social desirability bias.

\section{Conclusion}

This study found that different types of medical staff in Tianjin experienced low level burnout rates between and $36 \%$ and $76 \%$, moderate level burnout rates ranging between $20-43.5 \%$ and high level burnout rates ranging from 4.0-8.7\%. Our results revealed that empathy was negatively associated with burnout and job commitment had the negative effect on burnout. Job satisfaction had the positive effect on burnout, which was contrary to our hypothesis. Job satisfaction and job commitment played a mediating role in the relationship between empathy and burnout, which were strongly inter-correlated. We found the significant differences in burnout according to age, marital status and working hours. Additionally, the results indicated that the model was consistent across employment type and hospital type but was inconsistent across hospital level and job type. Based on our results, we recommend increased pay for medical staff and continued reform of the resourcing of different hospital levels; that hospital managers implement additional training; and that hospitals strengthen psychological testing and counseling.

\section{Abbreviations}

SD: Standard deviation; Std: Standardized path coefficient; Unstd: Unstandardized path coefficient; SE: Standard error; AGFI: Adjusted goodness of fit index; GFI: Goodness of fit; CFI: Comparative fit index; TLI: Tucker-Lewis index; RMSEA: Root mean square error of approximation; MLE: Maximum likelihood estimation; CR: Critical ration; Cl: Confidence interval.

\section{Declarations}

Acknowledgements

Not applicable

Authors' contribution 
ZY and YL designed this study and involved in the data analysis. JW, SN, EM made the revision of the manuscript. YQ and CL participated in the literature research. All authors read and approved the final manuscript.

\section{Funding}

This research did not receive any funding.

\section{Availability of data and materials}

All data used or analyzed during the study are available from the corresponding author on reasonable request.

\section{Ethics approval and consent to participate}

Ethical approval was granted from the Ethic Committee of Tianjin University of Traditional Chinese Medicine (71303171) and the study team obtained informed consent from all participants. Participants were made aware that they could withdraw at any time.

\section{Consent for publication}

Not applicable.

\section{Competing interests}

The authors declare that they have no competing interests.

\section{References}

1. Freudenberger HJ. Staff burn-out. J of social issues. 1974;30(1):159-65.

2. Khan A, Teoh KR, Islam S, Hassard J. (2018). Psychosocial work characteristics, burnout, psychological morbidity symptoms and early retirement intentions: a cross-sectional study of NHS consultants in the UK. BMJ Open, 2018;8(7), 1-11).

3. Vijendren A, Yung M, Shiralkar U. Are ENT surgeons in the UK at risk of stress, psychological morbidities and burnout? A national questionnaire survey. The Surgeon. 2018;16(1):12-9.

4. Imo UO. Burnout and psychiatric morbidity among doctors in the UK: a systematic literature review of prevalence and associated factors. BJ Psych Bulletin. 2017;41(4):197-204.

5. Laker C, Cella M, Callard F, Wykes T. Why is change a challenge in acute mental health wards? A cross-sectional investigation of the relationships between burnout, occupational status and nurses' perceptions of barriers to change. Int J Ment Heal Nursi. 2019;28(1):190-8.

6. Font A, Corti V, Berger R. Burnout in Healthcare Professionals in Oncology. Procedia Econ Fina. 2015;23:228-32. 
7. Yang S, Meredith P, Khan A. Stress and burnout among healthcare professionals working in a mental health setting in Singapore. Asian Journal of Psychiatry. 2015;15:15-20.

8. Souza FD, Egan SJ, Rees CS. The Relationship Between Perfectionism, Stress and Burnout in Clinical Psychologists. Behaviour Change. 2011;28(1):17-28.

9. Linzer $M$, Levine R, Meltzer $D$, et al. 10 bold steps to prevent burnout in general internal medicine. $J$ Gen Intern Med. 2014;29:18-20.

10. Dréano-Hartz S, Rhondali W, Ledoux M, Ruer M, Berthiller J, Schott A, et al Burnout Kamal AH, Bull JH, Wolf SP, Swetz KM, Shanafelt TD, Ast K, et al. Prevalence and Predictors of Burnout Among Hospice and Palliative Care Clinicians in the U.S. J Pain Symptom Manage. 2016;51(4):690-6.

11. Song SY, Zhao XC. Investigation analysis affecting factors of job burnout in medical staff. Chin Modern Med. 2011;18(34):5-7.

12. Chen Q, Liu X, Meng K. Job Burnout and Associated Factors among Young Health Care Providers in Tertiary Grade A Hospitals in Beijing. Chin General Pract. 2018;21(02):223-31.

13. Zhang PJ, Tang LL, Qian LH, et al. Current status of job burnout and effort-reward imbalance among full-time healthcare-associated infection management staff in Wuhu City. Chia J of Infection Control. 2019;18(12):1159-64.

14. Xu X, Hu M, Song Y, et al. Effect of positive psychological intervention on posttraumatic growth among primary healthcare workers in China: A preliminary prospective study. Sci Rep. 2016;6(1):1-7.

15. Li YX. Job Burnout and Measurements. Psych Sci, 2003;(03):556-557.

16. Hall LH, Johnson J, Watt I, Tsipa A, O'Connor DB. Healthcare Staff Wellbeing, Burnout, and Patient Safety: A Systematic Review. PLoS ONE. 2016;11(7):e0159015.

17. Caro MM, San-Martín M, Delgado-Bolton R, et al. Empathy, loneliness, burnout, and life satisfaction in Chilean nurses of palliative care and homecare services. Enfermería Clínica (English Edition). 2017;27(6):379-86.

18. Vasiliki, Bogiatzaki, et al. Empathy and Burnout of Healthcare Professionals in Public Hospitals of Greece. International Journal of Caring Sciences. 2019;12(2):611.

19. Giulia Lamiani P, Dordoni E Vegni (2020) Empathy, loneliness, burnout, and life satisfaction in Chilean nurses of palliative care and homecare services. Frontier in Psychology, 2017;10,27(6):379386.

20. Rocío J-S, Miguel Richart-Martínez, Noelia García-Aracil, et al. Measuring the levels of burnout syndrome and empathy of Spanish emergency medical service professionals. Aust Emer Care, 2019;22(3):193-199.

21. Yuguero O, Ramon Marsal J, Esquerda M, Vivanco L, Soler-González J. Association between low empathy and high burnout among primary care physicians and nurses in Lleida, Spain. Eur $\mathrm{J}$ Gen Pract. 2017;10(23(1):4-10.

22. Vasiliki, Bogiatzaki, et al. Empathy and Burnout of Healthcare Professionals in Public Hospitals of Greece. Int J Caring Sci. 2019;12(2):611. 
23. Lamothe M, Boujut E, Zenasni F, Sultan S. To be or not to be empathic: The combined role of empathic concern and perspective taking in understanding burnout in general practice. BMC Fam Prac. 2014;15:15.

24. Thirioux B, Birault F, Jaafari N. (2016). Empathy is a protective factor of burnout in physicians: New neuro-phenomenological hypotheses regarding empathy and sympathy in care relationship. Frontiers in Psychology,2016;5(7):763.

25. Yuguero O, Ramon Marsal J, Esquerda M, Vivanco L, Soler-González J. Association between low empathy and high burnout among primary care physicians and nurses in Lleida, Spain. Eur J Gen Pract. 2017;10(23(1):4-10.

26. Passalacqua SA, Sergin C. The effect of resident physician stress, burnout, and empathy on patientcentered communication during the long- call shift. Health Commun. 2012;27(5):449-56.

27. Lee H, Song R, Cho YS, Lee GZ, Daly BA. Comprehensive model for predicting burnout in Korean nurses. J Adv Nurs. 2003;44(5):534-45.

28. Piko BF. Burnout, role conflict, job satisfaction and psychosocial health among Hungarian health care staff: a questionnaire survey. Int J Nurs Stu. 2006;43(3):311-8.

29. Spector PE. Industrial and organizational psychology: Research and practice. John Wiley \& Sons; 1996.

30. Lin J-Y, Cheng-Jyh L. \& Chao-Jen Cheng. A Study of the Relationship between Job Stress, Job Burnout, Job Satisfaction and Organizational Commitment among Medical Radiologists in Taiwan. Journal of Information Optimization Sciences. 2013;34:2-03, 149-167.

31. Bumjung Kim L, Liu. Hisanori Ishikawa \& Sang-Hee Park. Relationships between social support, job autonomy, job satisfaction, and burnout among care workers in long-term care facilities in Hawaii. Educ Gerontol. 2019;45(1):57-68.

32. Tarcan M, Hikmet N, Schooley B, et al. An analysis of the relationship between burnout, sociodemographic and workplace factors and job satisfaction among emergency department health professionals. App Nurs Res. 2017;4(34):40-7.

33. Saeidi R, Izanloo A, Izanlou S. (2020) A Study of the Relationship between Job Satisfaction and Burnout among Neonatal Intensive Care Unit Staff. Iranian J Neona,2020;11 (1): 67-70.

34. SCHAUFELWI BUUNKB. Professional burnout. Handbook of Work and Health Psychology, 1996; 311346.

35. Erian CKTG, Erian MMAS. Commitment and burnout: where should surgeons draw the line? Ir J Med Sci. 2020;189(2):719-21.

36. Grabowski D, Chudzicka-Czupała A, Chrupała-Pniak M, Rachwaniec-Szczecińska Ż, Stasiła-Sieradzka M, Wojciechowska W. Work ethic, organizational commitment and burnout. Med Pr. 2019;70(3):30516.

37. Sturzu L, Lala A, Bisch M, Guitter M, Dobre D, Schwan R. Empathy and Burnout - A Cross-Sectional Study Among Mental Healthcare Providers in France. J Med Life. 2019;12(1):21-9. 
38. Chen $\mathrm{KY}$, Yang $\mathrm{CM}$, Lien $\mathrm{CH}$, et al. Burnout, job satisfaction, and medical malpractice among physicians[J]. Int J of Med Sci. 2013;10(11):1471.

39. Omdahl BL, O'Donnell C. Emotional contagion, empathic concern and communicative responsiveness as variables affecting nurses' stress and occupational commitment. Journal of Adv Nursing. 2010;29(6):1351-9.

40. Lin J-Y, Cheng-Jyh Lin \& Chao-Jen C. A Study of the Relationship between Job Stress, Job Burnout, Job Satisfaction and Organizational Commitment among Medical Radiologists in Taiwan. Journal of Information Optimization Sciences. 2013;34:2-03. DOI:10.1080/02522667.2013.821334. 149167.

41. Raižiene S, Endriulaitiene A. The relations among empathy, occupational commitment, and emotional exhaustion of nurses. Medicina. 2007;43(5):425-31.

42. Zou YX, Huang ZX, Qi J, et al. Prevalence and Factors Associated with Occupational Burnout among Staff of Community Health Centers in Guangzhou City. Chin General Practi. 2014;17(06):679-82. (in Chinese).

43. Martinez-Lopez FJ, Gazquez-Abad JC, Sousa CMP. (2013) Structural equation modelling in marketing and business research Critical issues and practical recommendations. European Journal of Marketing,2013;2(47), 115-152.

44. Kendall MG, Alan S. The advanced theory of statistics, Vols.II and II. New York: Hanfner Publisher Company; 1961.

45. Feng C. Medical Multivariate Statistical Analysis Method. Beijing: China Statistic Press; 2000.

46. Sueoka N, Nisigaki H, Yonezawa M, Tsukui T, Sakamoto C, Tabuchi M. The factorial validity of the Maslach burnout inventory-general survey (MBI-GS) across occupational groups and nations. J Organ Behav. 1988;9(2):103-11.

47. An XQ. Study on Chinese Version of the Jefferson Scale of Empathy-Health Professionals(JSE-HP) in Nurses. Taiyuan: Shanxi Medical University:2008. (in Chinese).

48. Zhang W, Meng H, Yang S, Liu D. The Influence of Professional Identity, Job Satisfaction, and Work Engagement on Turnover Intention among Township Health Inspectors in China. Int J Environ Res Public Health. 2018;15(5):988.

49. Coward RT, Hogan TL, Duncan RP, Horne CH, Hilker MA, Felsen LM. Job satisfaction of nurses employed in rural and urban long-term care facilities. Res Nurs Health. 1995;18(3):271-84.

50. HOELTER WJ. The analysis of Covariance Structures Goodness-of-Fit Indices. Sociological Methods Research. 1993;11(3):325-44.

51. Sturzu L, Lala A, Bisch M, Guitter M, Dobre D, Schwan R. Empathy and Burnout - A Cross-Sectional Study Among Mental Healthcare Providers in France. Journal of medicine life. 2019;12(1):21-9.

52. XU Z, YAN CL. Study on Job Burnout and Turnover Intention of Medical Staff in Heilongjiang Province. Chin Hosp Man. 2019;39(2):50-2. (in Chinese). 
53. Ahmad W, Ashraf H, Talat A, Khan AA, Baig AA, Zia I, Sarfraz Z, Sajid H, Tahir M, Sadiq U, Imtiaz H. Association of burnout with doctor-patient relationship and common stressors among postgraduate trainees and house officers in Lahore-a cross-sectional study. PeerJ. 2018;10(6):,e5519.

54. Liang WY, Chen Y, Tong YS, Li J, Zhao LT, An J. Relationship between the job burnout and personality trait in psychiatrists. Chin Men Heal J. 2018;32(12):1025-28. (in Chinese).

55. Chen Y, Gu CY. Occupational burnout of staffs in one mental health center. Chin Heal Resource,2012;15(02),162 - 64. (in Chinese).

56. Han JY, Liao YY, Ma YH. Investigation and analysis on job burnout of primary pharmacists. Chin J Hosp Phar. 2015;35(15):1430-33. (in Chinese).

57. Zhang BY, Zhang X, Zhao XM, Tong XX, Zhang N, Liu XW, Fan C, Li JY, Liu GX, Zhao XW. Analysis of the job burnout of medical staff in urban community and township health centers. Chin Hosp Admin. 2017;37(04):58-60. (in Chinese).

58. Liu Y, Liu GX. Job burnout in clinicians: current status and related factors. J Third Military Med Univ. 2020;42(03):288-93. (in Chinese).

59. Rössler W, Hengartner MP, Ajdacic-Gross V, et al. Predictors of burnout: results from a prospective community study. Eur Arch Psychiatry Clin Neurosci. 2015;265:19-25.

60. Yuguero Torres O, Esquerda Aresté M, Marsal Mora JR, Soler-González J. Association between Sick Leave Prescribing Practices and Physician Burnout and Empathy. PLOS ONE. 2015;10(7):e0133379.

61. An H, Liang CG. Mediating effects of occupational commitment of nurses in the relationship between empathy ability and job burnout. Modern Preventive Med. 2018;45(06):990-3. (in Chinese).

62. Cui G, Wang F, Xu Y, et al. Moderating effects of doctors' occupation commitment on relationship between the job demand and job burnout. Chin Mental Heal J. 2015;29(02):134-8. (in Chinese).

63. Mcdermott D. Professional Burnout and its Relation to Job Characteristics, Satisfaction, and Control. J Human Stress. 1984;10(2):79-85.

64. Laverdière O, Ogrodniczuk JS, Kealy D. Clinicians' Empathy and Professional Quality of Life. Journal of Nervous Mental Disease. 2019;207(2):49-52.

65. Lok P, Crawford J. Antecedents of organizational commitment and the mediating role of job satisfaction. J Managerial Psych. 2001;16(8):594-613.

66. Tang EZ. Chinese firms' "export-productivity paradox": theory extending and testing again. Management World. 2017;02:30-42. (in Chinese).

67. Jia Z. Exploring the classification characteristics of nurses' empathic ability and the differences of coping styles among different classifications. Chin Nursing Management. 2018;8(04):453-7. (in Chinese).

68. Ma TJ, Li JH, Zhang L, et al. Job Satisfaction and Influencing Factors of Medical Staff in a Community in Changchun City Under Family Doctor Contract Service Mode. Med Soci. 2019;32(02):30-3 + 51. (in Chinese). 
69. Huang D, Yin W, Yu Q, Sun K, Guo H. Influencing factors of physicians' turnover intention at public county hospitals: a career stage perspective. Chin J Hosp Admin. 2014;30:930-4. (in Chinese).

70. Liu XZ, Li YH, Tang H. The level and factors associated with empathy among medical personnel. J of Nursing Sci. 2017;32(04):54-7.

71. Hojat M, Gonnella JS, Nasca TJ, et al. Physician empathy: definition, components, measurement, and relationship to gender and specialty. Amer J Psych. 2002;59(9):1563-9.

72. Siegrist J. Stress in the workplace: Past, present and future. London: Whurr Publishers; 2001.

73. Schooley B, Hikmet N, Tarcan M, et al. Comparing Burnout Across Emergency Physicians, Nurses, Technicians, and Health Information Technicians Working for the Same Organization. Medicine. 2016;95(10):e2856.

74. Zhao JB, Chen RN, Yin SY, et al. Mediating effects of regulatory emotional self-efficacy of clinicians between compassion fatigue and depression. Modern Preventive Medicine. 2018;45(03):476-9..(in Chinese).

75. Tong Z, et al. Status of job burnout and its influencing factors among young medical staff in Beijing. Pract Prev Med,2020;(09),1118-1121.

\section{Figures}

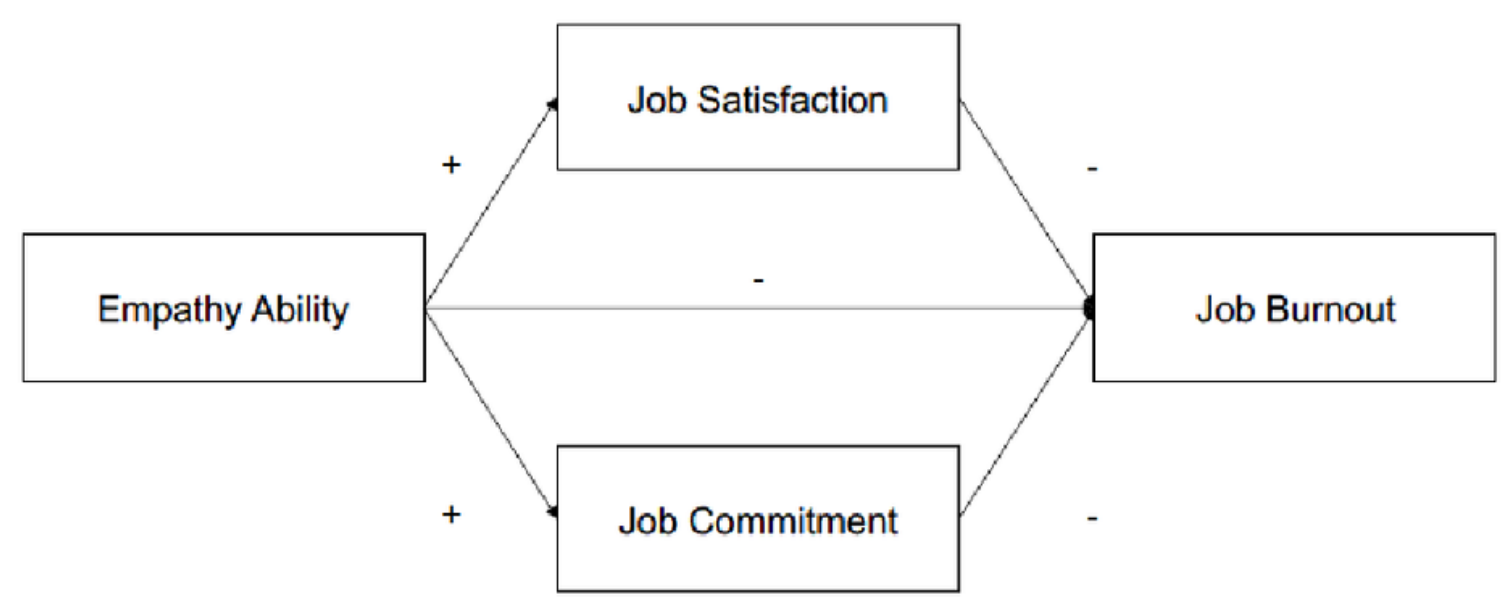

\section{Figure 1}

Empathy-Burnout Model 


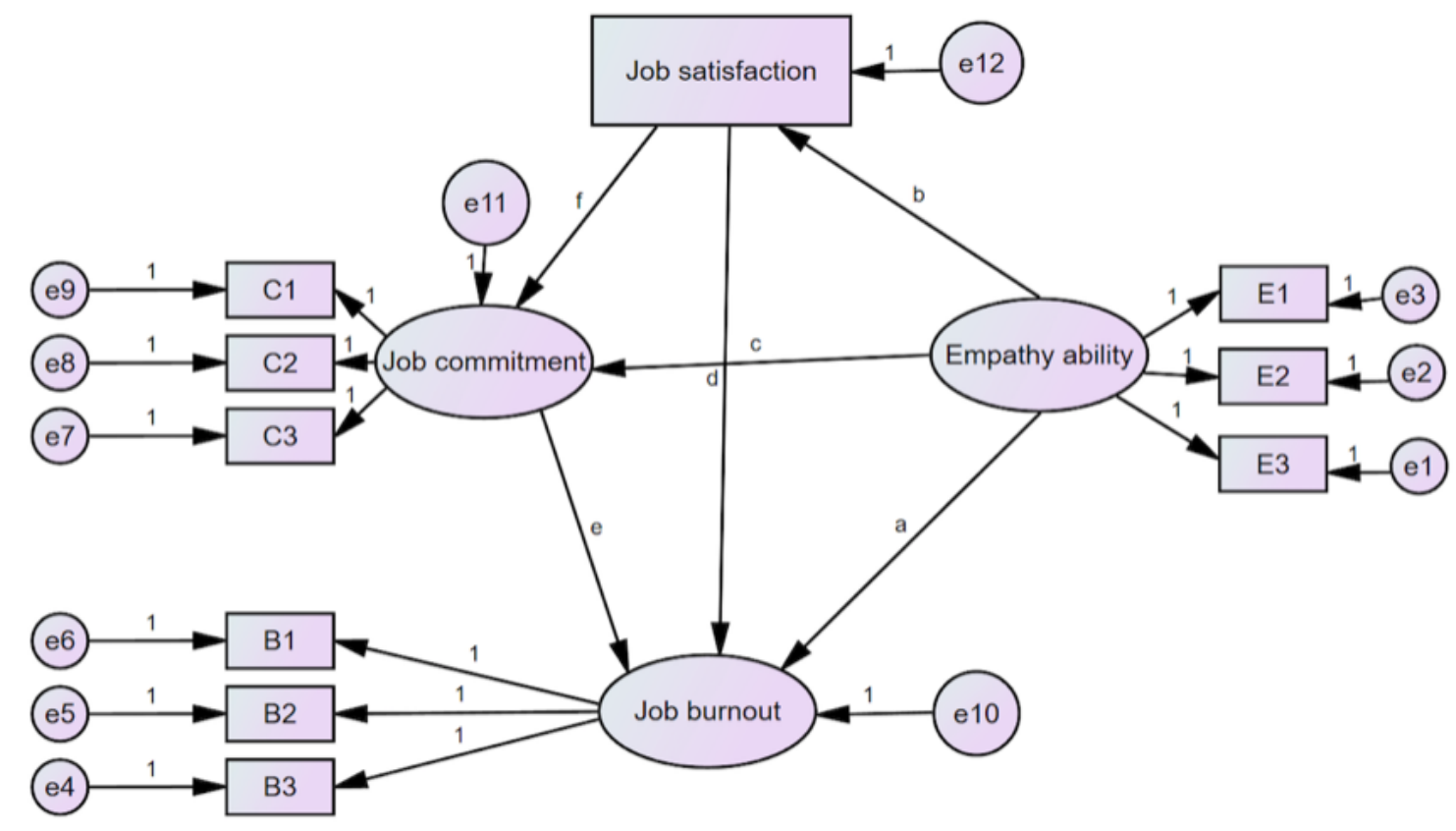

Figure 2

Structural equation hypothetical model of the relationship between empathy, job burnout, job satisfaction and job commitment

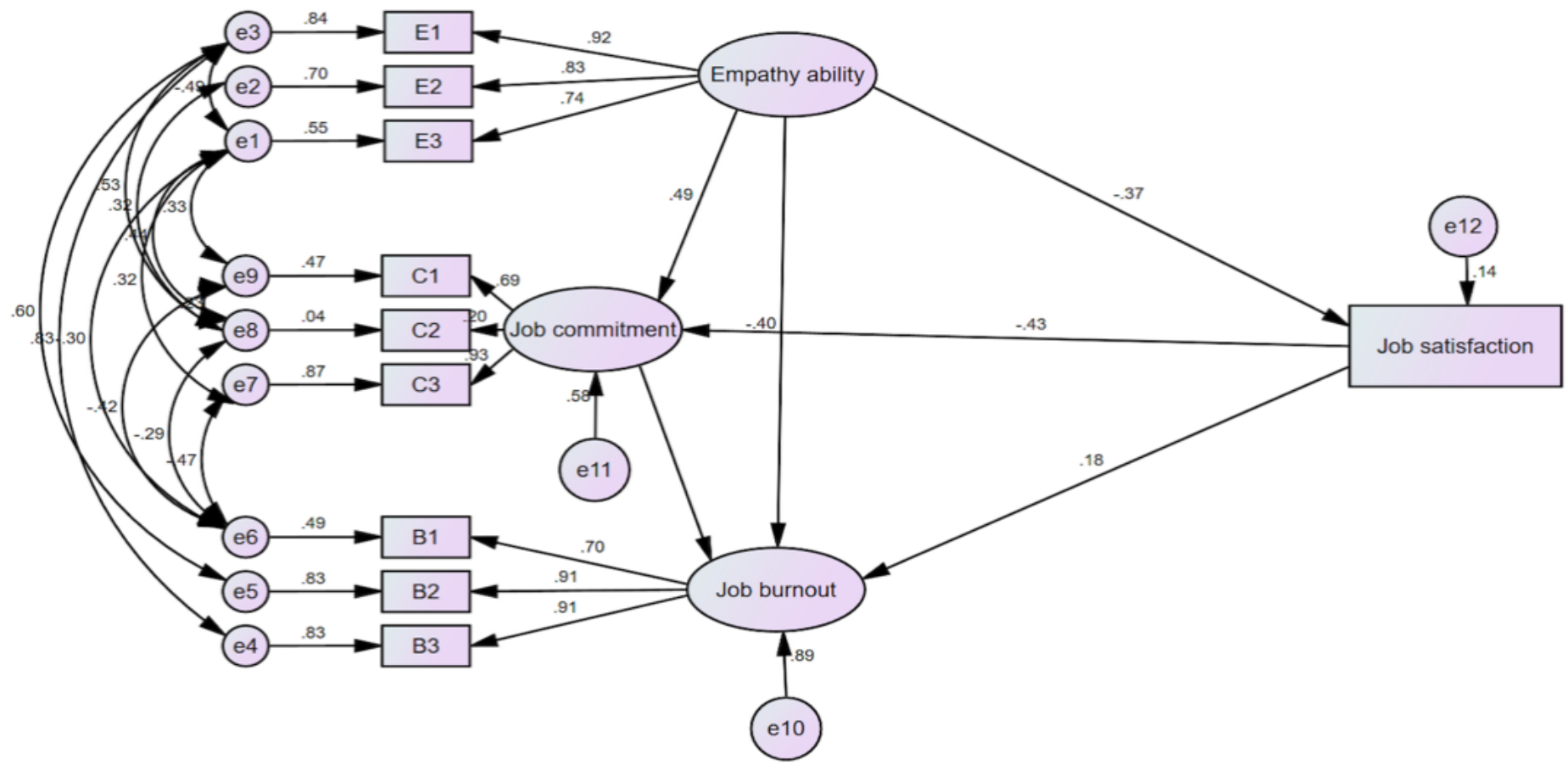

Figure 3 
Revised structural equation model of the relationship between empathy, job burnout, job satisfaction and job commitment 